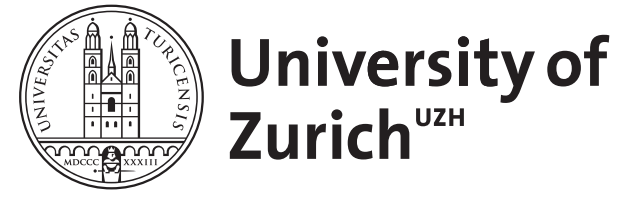

Zurich Open Repository and Archive

University of Zurich

University Library

Strickhofstrasse 39

CH-8057 Zurich

www.zora.uzh.ch

Year: 1965

Interest Rates, Forced Saving, and Prices in the Long Run

Niehans, Jurg

DOI: https://doi.org/10.2307/2295839

Posted at the Zurich Open Repository and Archive, University of Zurich

ZORA URL: https://doi.org/10.5167/uzh-155045

Journal Article

Published Version

Originally published at:

Niehans, Jurg (1965). Interest Rates, Forced Saving, and Prices in the Long Run. Review of Economic

Studies, 32(4):327.

DOI: https://doi.org/10.2307/2295839 


\section{Interest Rates, Forced Saving, and Prices in the Long Run}

\section{Introduction}

The main teaching of economics about the influence of interest rates on prices can be summarized in the proposition that cheap money makes dear bread. More precisely this may be interpreted to mean that if the level of interest rates is determined exogenously by the monetary authorities, any lowering of this level will make the development of prices more inflationary (or less deflationary) than it would have been at the old level. In mathematical terms this can be expressed by saying that the derivative of the rate of price change with respect to the rate of interest is negative. This general proposition will, for the purpose of this paper, be called the " classical " doctrine. Though seldom precisely stated or analyzed, it is probably one of the most universally accepted propositions of economics. Outside the economic profession, however, things are different. In particular, one often finds the argument that the classical doctrine, while valid in the short run, may be invalid in the long run. To the best of my knowledge, this argument has never been analyzed in detail. The present paper thus addresses itself to the question whether in the long-run context of economic growth lower interest rates might conceivably lead to lower prices.

The causal chain from interest rates to prices may involve many different elements, some of which have been discussed in recent contributions, particularly by Solow [9], Tobin [11], and Hahn [3]. ${ }^{1}$ Looking back on the long history of the classical doctrine one finds, however, that a dominant rôle was traditionally accorded to what was often called "forced saving ". ${ }^{2}$ It is on this element that the present paper will focus attention, while other mechanisms, interesting and important as they may be, are left out of account. It will be shown that in the long run the effect of interest rates on prices by way of forced savings may be the opposite from what the classical doctrine asserts. Classical assumptions may thus lead to unclassical results. ${ }^{3}$

The argument will be developed in four stages. The problem is first considered in the context of a stationary model in which investment has no capacity effects. It may fairly be called a Wicksell-type model. In the second model there is still no growth, but the capacity effects of investment now become important. Since it was Cassel who emphasized these effects, it may be said to be a Cassel-type model. The stage of Solow-type models is reached with the introduction of long-range growth at an exogenously given rate. In the fourth section the growth of the labor force will finally be considered as endogenous, its rate being determined in a Malthusian fashion by per capital real income. It will be seen that each of these changes in the underlying "vision " of the process has important consequences for the long-run effect of interest rates on prices.

I. The Wicksell-Type Model: Stationary Economy without Capacity Effects

Wicksell may be called the leading protagonist of the classical doctrine in modern economics. His position can be summarized in the following two statements:

${ }^{1}$ Some aspects were also discussed in [7].

${ }^{2}$ On the history of this concept cf. [4] and [5].

${ }^{8}$ In working out an earlier version of this article, Professor Edwin S. Mills helped me to clear up an important mathematical point. While his contribution cannot be identified in the present text, the insight I gained from it was probably a necessary condition for my finishing it. 
(1) As long as the market rate of interest is kept below the equilibrium rate, prices will continue to rise.

(2) If after a while the market rate is put up to the equilibrium level, prices will stabilize at their maximum. ${ }^{1}$

This amounts to saying that the derivative of the rate of price change with respect to the rate of interest is negative if we start from that particular level of interest at which prices are stable. By thus specifying a particular starting point, Wicksell, instead of considering the classical thesis in general, actually concentrated on an important special case. ${ }^{2}$ The following model is designed to express as concisely as possible the essential elements of the reasoning on which Wicksell seems to have based his conclusions. It does not pretend to be a literal translation into the language of symbols of what Wicksell said in so many words, but the author hopes that Wicksell, had he lived to see the age of growth theory, would not have rejected this summary of his ideas as unfair.

The price level is defined as the ratio between money income and real income, both net of depreciation:

$$
p=\frac{Y}{X}
$$

Money income is assumed to be divided between consumption and net investment

$$
Y=C+I \text {. }
$$

Consumption, in turn depends on money income and its rate of change: ${ }^{3}$

$$
C=c\left(Y-\frac{d Y}{d t}\right) .
$$

The introduction of the rate of income change into the consumption function is economically equivalent to making to-day's consumption depend on yesterday's income, i.e. to introducing a Robertsonian lag. This is an essential element of the theory, because it provides for the possibility of "forced" or "involuntary" savings which since the days of Malthus and Bentham play so prominent a part in the classical doctrine: While voluntary savings are equal to $(1-c) . Y$, the component $c . d Y / d t$ represents involuntary savings. ${ }^{4}$ It is of particular importance to note that involuntary savings can be called forth not only by increases in real income, but also by mere inflation. Indeed, in the present context it is the main economic function of price increases to produce the involuntary savings necessary to close any gap between voluntary savings and investment. For the Wickselltype model we are forced to assume that $c==1$, so that voluntary saving is zero. This assumption is necessary to make the stationary state to which the Wicksellian economy gravitates (cf. [12], p. 136) consistent with a stable price level at a constant rate of interest.

For simplicity's sake the demand for investment in money terms may be equated to the difference between the desired stock of capital $(R)$ and the actual stock $(K)$, valued at current prices:

$$
I=p(R-K) \text {. }
$$

${ }^{1}$ Cf. [12], p. 147; [13], vol. II, p. 190 f.

${ }^{2}$ Since the time of Ricardo and Thornton most theoretical analyses of the classical proposition seem to be based on this special case, whereas most practical applications seem to rest on the more general thesis.

${ }^{3}$ Possible repercussions of interest rates on consumption and saving are neglected as non-essential

- If involuntary savings were left out of account, the real magnitudes of the system could be determined without reference to the price level, whereas the course of prices would remain indeterminate. As a consequence, the economy would no longer be able to accommodate an exogenously given rate of interest, i.e. such a rate would make the system overdetermined. This kind of inconsistency of neo-classical growth models with autonomous interest rates was recently emphasized by R. C. O. Matthews [6]. The introduction of " forced "savings, induced by price changes, may fairly be called the classical way of coping with this problem. Some other ways of gaining the necessary degree of freedom are discussed in Matthews' paper. 
$R$ is assumed to be related to planned or desired output by a Cobb-Douglas production function: ${ }^{1}$

(5)

$$
X=L^{1-\alpha} R^{\alpha}
$$$$
(0<\alpha<1) \text {. }
$$

Enterpreneurs will want to employ capital up to the point where its marginal return is equal to the market rate of interest, $\bar{r}$ :

$$
\bar{r}=\frac{\partial X}{\partial R} \text {. }
$$

This implies that the expectation of changing prices is of no importance for the investment process. An element which may be important in the real world is thus neglected. This is done not only to keep the analysis more manageable but also in order to concentrate on those aspects of the problem which used to be basic in establishing the classical thesis. It should be noted that $\bar{r}$ is not actually the rate of interest on loans but the rate of return on real capital goods. In most cases it will, therefore, be higher than the rate on, say, high-grade bonds. Wicksell would have answered, however, that there is a definite relation between the two rates in such a way that whenever the government or the central bank should announce that they are prepared to supply loans at a lower rate than before, the " parity rate" of real capital returns would be lowered correspondingly. The basic question thus is whether a given reduction of $\bar{r}$, induced by an autonomous lowering of the loan rate, will lead to an increase in the price level.

The actual stock of capital, on the other hand, is related to actual output:

The rate of actual return on capital or the " natural " rate of interest is, therefore,

$$
r=\frac{\partial X}{\partial K}
$$

Labor is assumed to be constant. ${ }^{2}$ The same is true for $K$, whatever investment may be (cf. [12], p. 145). This means that in a Wicksell-type analysis there is no room for capacity effects of investment. Investment goods are demanded all right, but they are not added to the capital stock used in current production. As a consequence, the gap between desired and actual capital is never really diminished, and actual output also remains constant (cf. [12], p. 143). We now have 8 equations in 11 variables. Once $L$ and $K$ are given, we can thus determine the course of prices corresponding to any given $\bar{r}:^{3}$

$$
\frac{\dot{p}}{p}=\alpha r^{\frac{\alpha}{1-\alpha}}\left(\bar{r}^{\frac{1}{\alpha-1}}-r^{\frac{1}{\alpha-1}}\right) .
$$

Since $0<\alpha<1$, the following statements can be made:

(1) The price level is stable if, and only if, the "market rate of return ", $\bar{r}$, is kept equal to the marginal product of capital actually in use, $r$, i.e. to Wicksell's " natural rate".

${ }^{1}$ Though no other types of production functions are considered in this paper, I am inclined to think that similar results could be obtained for other types as well.

${ }^{2}$ The model implies that real wages equal the marginal product of labor while money wages move with the price level. Following Wicksell, we thus make no use of a wage lag. Whatever may be said about distribution is clearly implied in the model, but as long as $c=1$, distributional aspects are unimportant for the results anyhow.

${ }^{3}$ Remembering that $c=1$ and $\dot{X}=0$, successive use of (1), (3), (2), and (4) gives

$$
\frac{\dot{p}}{p}=\frac{\dot{Y}}{Y}=\frac{\dot{Y}}{p X}=\frac{Y-C}{p X}=\frac{I}{p X}=\frac{R-K}{X} .
$$

But by virtue of (5), (6), (7) and (8) respectively, we have

$$
\bar{K}=L\left(\frac{\bar{r}}{\alpha}\right)^{\frac{1}{\alpha-1}} \text { and } K=L\left(\frac{r}{\alpha}\right)^{\frac{1}{\alpha-1}} \text {, while } \frac{L}{X}=\alpha r^{\frac{\alpha}{1-\alpha}} \alpha^{\frac{1}{\alpha-1}} .
$$


(2) Any reduction of $\bar{r}$ below $r$ will make prices rise and vice versa.

(3) Prices will continuously rise at a constant rate as long as $\tilde{r}$ is kept below $r$ by a constant margin.

(4) Prices will increase the faster the bigger the margin between $\bar{r}$ and $r$.

(5) If $\tilde{r}$, after being kept below $r$ for a certain time, is again put up to $r$, prices will remain constant at their maximum.

These statements are, of course, just Wicksellian implications of the fact that the derivative of the rate of price change with respect to the rate of interest

$$
\frac{d}{d \bar{r}}\left(\frac{\dot{p}}{p}\right)=-\frac{\alpha}{1-\alpha} r^{\frac{\alpha}{1-\alpha}} \bar{r}^{\frac{\alpha-2}{1-\alpha}}
$$

is negative, i.e. that the classical doctrine is fully valid.

I believe this is about the basic reasoning on which, more or less articulately, Wicksell's argument in support of the classical doctrine is based. The way it was presented here, it should be obvious that it can at best be defended in the short run when the newly produced investment goods cannot yet be put to use. In the long run it becomes clearly unreasonable to assume that the same gap between the desired and the actual capital stock remains open year by year no matter what quantity of investment goods have been produced in the meantime. As long as the classical doctrine is based on a Wicksell-type analysis only, it cannot, therefore, be regarded as well-established for the long run.

\section{The Cassel-Type Model: Stationary Economy with Capacity Effects}

It seems to have been Cassel who, in his discussion of Wicksell's cumulative process, for the first time explicitly introduced the capacity effects of investment (cf. [2], p. 395, 449). In his analysis newly produced investment goods are continuously added to the capital stock used in current production, thereby expanding real output and diminishing the marginal productivity of capital. This modification can be expressed in our model by equating actual to desired magnitudes, thus dropping equations (5) and (6), and replacing (4) by

$$
I=p \frac{d K}{d t}
$$

This implies that the capital stock is continuously kept at the desired level by new investment. The lags which certainly appear in this process in the real world are not considered here, since in the long run they do not seem to be an essential part of the analysis. ${ }^{1}$ This leaves us with 6 equations in 8 variables. Once the supply of labor is given, we thus can again determine the course of prices for autonomously given rates of interest.

From (3), (2), and (4a) we now have

$$
\frac{\dot{Y}}{Y}=1-\frac{1}{c} \cdot \frac{C}{Y}=\frac{c-1}{c}+\frac{1}{c} \cdot \frac{I}{Y}=\frac{c-1}{c}+\frac{1}{c} \cdot \frac{\dot{K}}{X}
$$

The production function (7), on the other hand, gives

$$
\frac{\dot{X}}{X}=\alpha \frac{\dot{K}}{K}+(1-\alpha) \frac{\dot{L}}{L}
$$

Thus

$$
\frac{\dot{p}}{p}=\frac{\dot{Y}}{Y}-\frac{\dot{X}}{X}=\frac{c-1}{c}+\left(\frac{1}{c} \frac{K}{X}-\alpha\right) \frac{\dot{K}}{K}-(1-\alpha) \frac{\dot{L}}{L} .
$$

${ }^{1}$ However, as Beckmann reminded me, these lags may affect the stability of the system. 
But since, by (8) and (7),

we have

$$
r=\frac{\partial X}{\partial K}=\alpha L^{1-\alpha} K^{\alpha-1} \text {, i.e. } K=\alpha^{\frac{1}{1-\alpha}} L r-\frac{1}{1-\alpha},
$$

$$
\frac{\dot{K}}{K}=\frac{\dot{L}}{L}-\frac{1}{1-\alpha} \frac{\dot{r}}{r}, \text { while } \frac{K}{X}=K L^{\alpha-1} K^{-\alpha}=\frac{\alpha}{r} .
$$

Substituting into the previous expression and rearranging we obtain

$$
\frac{\dot{p}}{p}=\frac{c-1}{c}+\left(\frac{\alpha}{c r}-1\right) \frac{L}{L}-\frac{\alpha}{1-\alpha}\left(\frac{1}{c r}-1\right) \frac{\dot{r}}{r} .
$$

Now the Cassel-type economy is still stationary, the growth model which Cassel developed in another context notwithstanding. As a consequence $L=0$ and $c=1$. The course of prices is thus simply given by

$$
\frac{\dot{p}}{p}=-\frac{\alpha}{1-\alpha}\left(\frac{1}{r}-1\right) \frac{\dot{r}}{r}
$$

Assuming $r<1$, this leads to the following conclusions:

(1) The price level will be stable at any rate of interest whatever, provided this rate is kept constant. There is thus no particular " natural rate" at which the market rate must be kept in order to maintain price stability. In the long run, any interest rate will become the equilibrium rate.

(2) Prices are rising if, and only if, interest rates are in the process of falling and vice versa $;{ }^{1}$ it is not the level but the change of interest that dominates prices.

(3) If interest rates are first lowered and then raised again to their previous level, prices will first rise and then fall again; they will not remain at their maximum.

Cassel thus seems to have been right in insisting that as soon as capacity effects are allowed for, Wicksell's conclusions are sharply denied: in due course, the stock of capital will adjust to any level of interest. Wicksell, though still relegating the capacity effects of investment to a secondary level of importance, explicitly, if grudgingly, admitted the validity of Cassel's point (cf. [13], vol. I, p. 251; vol. II, p. 195, 198 f). It thus seems that the validity of the classical doctrine is crucially dependent on the neglect of capacity effects of investment. Nevertheless there is still no reason to believe that by lowering the rate of interest prices can actually be lowered. The classical doctrine seems very much weakened, to be sure, but it is not turned upside down. But this is not the whole story.

\section{The Solow-Type Model: Economy with Exogenous Growth Rate.}

In the Cassel-type model the economy is unable to grow unless interest rates are kept falling all the time. All we have to do to get it moving is to make the input of labour grow at a given rate

$$
\frac{L}{L}=\lambda \text {. }
$$

We thus arrive at a model of the general type of that used by Solow in his famous " Contribution to the Theory of Economic Growth" [10]. Once we have made room for economic growth there is no longer any reason to close the door to voluntary saving. We can thus allow for propensities to consume below unity, i.e. $c<1$. On the other hand, a propensity to consume above unity is now also a serious possibility, for if households decide on tomorrow's consumption on the basis of to-day's income while at the same time experiencing

\footnotetext{
${ }^{1}$ In the real world this conclusion would probably be tempered by the lag of actual investment behind desired investment so that prices need a certain time to level out even after interest rates have become stable again.
} 
a constant increase of current income over past income, they may well decide to allocate to consumption a little more than current income. The continuous increase in income may still provide for positive savings at stable prices. In this way, the recurring experience of involuntary savings or dissavings may be counteracted by an adjustment in the propensity to consume. ${ }^{1}$ The resulting solution for the rate of price change in terms of the rate of interest and its change is derived from (9) by simply letting $\dot{L} / L=\lambda$ :

$$
\frac{\dot{p}}{p}=\frac{c-1}{c}+\left(\frac{\alpha}{c r}-1\right) \lambda-\frac{\alpha}{1-\alpha}\left(\frac{1}{c r}-1\right) \frac{\dot{r}}{r} .
$$

Interpretation of this result yields the following observations:

(1) Stability of prices at constant interest rates now again requires a certain equilibrium level of interest. This equilibrium rate $r^{*}$ is easily determined by letting $\dot{r} / r=0$ and putting (III) equal to zero. By a little manipulation one obtains

$$
r^{*}=\alpha \frac{\lambda}{1-c(1-\lambda)} .
$$

It thus appears that in a growing economy Cassel's conclusions are no longer valid. Instead it is now Wicksell who again maintains the field. ${ }^{2}$ In part thanks to its very theoretical looseness, Wicksell's reasoning thus seems to have been a better guide to what happens in a growing economy than Cassel's more consistently stationary argument. Wicksell's hesitant concession to Cassel may well have been forced upon him by his inability to put in clear theoretical terms what he actually felt to be true.

(2) The course of prices at below-equilibrium interest rates can be determined by considering the derivative of (III) with respect to the rate of interest, again with $\dot{r} / r=0$ :

$$
\frac{d}{d r}\left(\frac{\dot{p}}{p}\right)=-\lambda \frac{\alpha}{c r^{2}}
$$

Since negative $\alpha, c$, and $r$ can be ruled out, the sign of this expression depends on the growth rate: if population grows, the sign is certainly negative; any autonomous reduction in interest rates will then make prices go up more (or go down less) than they would have done otherwise. Again Wicksell and the classical doctrine are thus confirmed. ${ }^{3}$ It is remarkable, however, that in a declining economy the reverse is true: if $\lambda<0$, lower interest rates will retard inflation or produce deflationary pressure. Cheap money will then indeed make cheap bread. This is so because a lower rate of interest, by encouraging more capitalintensive methods of production, then makes the required amount of annual disinvestment relatively high. As a consequence, the gap between required disinvestment and disinvestment at constant prices has to be closed by more "forced dissaving" induced by falling prices. Wicksell and the classical doctrine thus represent only one half of the truth, though presumably the more important one. Cassel, by assuming $\lambda=0$, nicely placed himself on the

${ }^{1}$ If the economy is assumed to be divided into labourers and capital owners with unequal propensities to consume, $c$ simply becomes a weighted average of $c_{L}$ and $c_{K}$ with constant weights depending on $\alpha$. The results remain the same.

2 About the same conclusion was expressed by Martin Beckmann in an important but still unpublished paper [1]. Beckmann uses a model which is in many ways similar to the one presented in this section. However, since he did not consider negative growth rates and endogenous growth, he did not identify the limitations to the Wicksellian argument which will be developed on the following pages. I am indebted to Beckmann for showing me his paper and also for important comments on a draft of mine.

${ }^{3}$ As Dr. Franz Ritzmann pointed out to me it may perhaps seem strange that the inflationary effect of lower interest rates is the stronger the lower the propensity to consume. On reflection this is, in fact, quite plausible. In our model inflation has the "function" to call forth involuntary savings. Now on the basis of our consumption function involuntary savings are positively related to the propensity to consume (cf. p. 000). If this propensity is relatively high we thus need relatively little inflation to call forth the required savings. Though readily explained it is still remarkable that in a growing economy a high propensity to consume may act as a brake on the inflationary effects of cheap money. 
fine dividing line between the two halves, where a lasting change in interest does not affect the rate of price change either way.

(3) To the price effects of the level of interest rates must now be added those of its changes represented by the "Casselian" term

$$
-\frac{\alpha}{1-\alpha}\left(\frac{1}{c r}-1\right) \frac{\dot{r}}{r}
$$

Since $\frac{\alpha}{1-\alpha}$ is positive, the direction of these effects depends on the sign of the bracketed term. If this sign is positive (i.e. $\frac{1}{r}>c$ ), every lowering of interest rates, taken by itself, will give the economy an inflationary shock. This is certainly the most probable case. The opposite assumption $\left(\right.$ i.e. $\left.\frac{1}{r}<c\right)$, though not inconceivable, seems to be very unlikely. Combining the two types of price effects we may suppose that monetary authorities first push interest rates down below their equilibrium level and then, after a period of "cheap money ", put them up again. The results for prices in a Solow-type model are illustrated in fig. 1. If the economy is growing $(\lambda>0)$, the price level will first move upward under

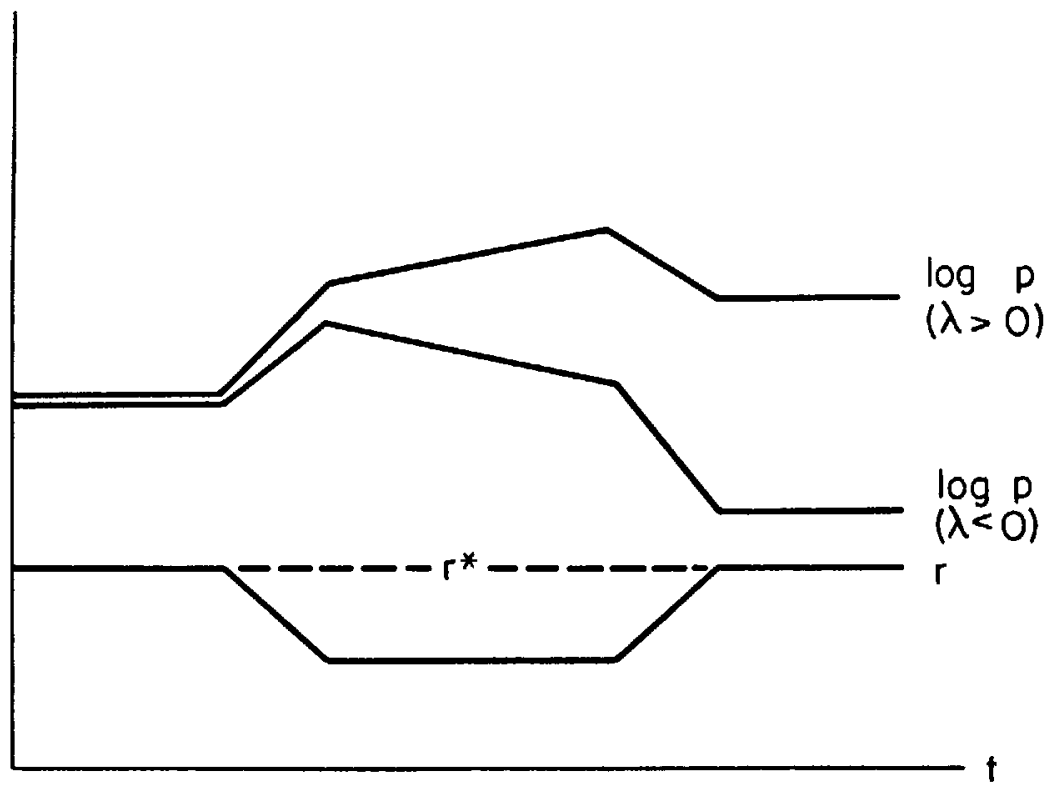

Figure 1

strong inflationary pressure. Once interest rates cease to fall, inflation will continue at a slower, but steady pace. The restoration of equilibrium rates will indeed correct the initial spurt in prices, but still prices will remain at a permanently higher level. In a declining economy $(\lambda<0)$, the compensating shock effects would be the same, but the permanent effect would be of opposite sign, so that the period of "cheap money" would leave the economy with permanently lower prices.

On the whole we thus find that in the context of a growing economy with an exogenously determined growth rate, the classical doctrine, seriously damaged for the stationary case by the Cassel-type analysis, is restored to about its full Wicksellian force. At the same time, however, it was found that in a declining economy the classical doctrine, far from being true, is turned upside down. The validity of the classical doctrine is thus seen to 
depend in an essential way on the characteristics of the growth process. Could it not be that these characteristics themselves depend on the rate of interest? To this question we now turn.

IV. The Malthus-Type Model: Economy with Endogenous Growth Rate.

There are various ways in which the rate of interest might influence the rate of growth. One straightforward possibility is to make the rate of population growth depend on real per capita income which in turn depends on the capital-intensity of production and thus on the rate of interest. This amounts to replacing the exogenously given rate of population growth by some kind of Malthusian theory in which labor appears as an endogenous variable. ${ }^{1}$ We shall restrict ourselves to the most simple hypothesis which makes the rate of population growth directly proportionate to the difference between per capita income $(X / L)$ and some minimum of subsistence $(m)$ :

$$
\frac{\dot{L}}{L}=\pi\left(\frac{X}{L}-m\right) . \quad(\pi>0 ; m>0)
$$

This is, of course, a very crude theory of population, but I should be surprised if the adding of refinements did change the basic conclusions in a fundamental way. ${ }^{2}$ It should be emphasized that using a Malthusian population theory is just one of many ways in which results of the type presented in this section could be reached. We might not even have to change the formal model. For example, $\pi(X / L-m)$ could be re-interpreted as representing the rate of improvement in the " quality " of a constant labor force resulting from spending a certain proportion of above-minimum income on additional education. Similar results could be obtained, though at the cost of a less plausible investment theory, by simply making investment a function of income. ${ }^{3}$ The main point is that higher interest rates somehow lead to slower growth.

Substituting our Malthusian theory into (9) and considering that

$$
\frac{X}{L}=\left(\frac{K}{L}\right)^{\alpha}=\left(\frac{\alpha}{r}\right)^{\frac{\alpha}{1-\alpha}},
$$

the rate of price change becomes

$$
\frac{\dot{p}}{p}=\frac{c-1}{c}+\left(\frac{\alpha}{c r}-1\right) \pi\left[\left(\frac{\alpha}{r}\right)^{\frac{\alpha}{1-\alpha}}-m\right]-\frac{\alpha}{1-\alpha}\left(\frac{1}{c r}-1\right) \frac{\dot{r}}{r} .
$$

The discussion of this expression will be restricted to the case $c<1$.

(1) First there is again the question of some equilibrium rate of return which, in the absence of any change of interest, would keep prices stable. By putting $\dot{p} / p=0$ and letting $\dot{r} / r=0$, the equilibrium rate of interest $r^{*}$ can be found to be implicitly given by

$$
\left(\frac{\alpha}{r^{*}}\right)^{\frac{\alpha}{1-\alpha}}-m=\frac{1}{\pi} \cdot \frac{1-c}{\frac{\alpha}{r^{*}}-c} .
$$

${ }^{1}$ Some wider implications for growth theory of making population endogenous were discussed in [8].

${ }^{2}$ Instead of on output per head, population growth may be assumed to depend on, say, the real wage, $\frac{\partial X}{\partial L}$. Since $\frac{\partial X}{\partial L}=(1-\alpha) \frac{X}{L}$, this would give a somewhat different course of prices, but the general nature of the results would remain the same.

${ }^{3}$ This approach was used in [7]. 
The left-hand side of this equation simply represents $(X / L-m)$. At zero interest, i.e. at an infinitely high capital-labor ratio, it is infinity, and with rising interest rates it falls asymptotically towards $-m$ (cf. fig. 2 ).

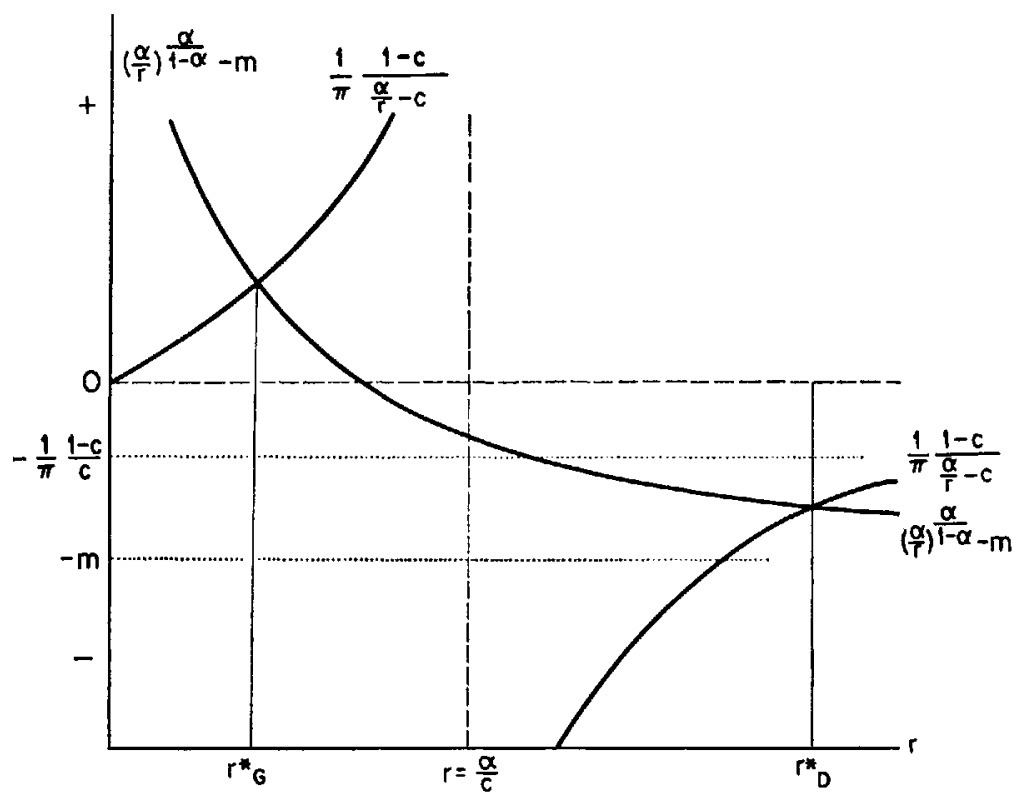

FIGURE 2

The right-hand side, on the other hand, is zero at zero interest and then rises to infinity as interest goes up to $r=\frac{\alpha}{c}$. There must thus be some positive rate of interest $r^{*}{ }_{G}$ at which the equation is satisfied, i.e. at which prices are stable. This Wicksellian equilibrium rate of interest also guarantees a positive rate of growth, for $\left(\frac{X}{L}-m\right)$ cannot help being positive at this point.

The remarkable thing is that there may be a second equilibrium rate of interest, for we find that at interest rates above $r=\frac{\alpha}{c}$ the right-hand expression is negative, going up from minus infinity to $-\frac{1}{\pi} \cdot \frac{1-c}{c}$ as interest rises to infinity. The above equilibrium condition may thus be satisfied also at some relatively high rate of interest $r^{*}{ }_{D}$. Since at this rate per capita income must be below the minimum of subsistence, it will maintain not an equilibrium of growth but of decline, i.e. growth will be negative. There is under those circumstances no longer a single rate of interest which must be maintained in order to keep prices stable, but there is a choice between an expansionary and a contractive equilibrium rate. An equilibrium of decline does not always exist, to be sure, for its existence requires

$$
m>\frac{1}{\pi} \cdot \frac{1-c}{c} .
$$

Otherwise the two curves representing, respectively, the left-hand and the right-hand side of the equilibrium condition do not intersect above $r=\frac{\alpha}{c}$ no matter how high the rate of 
interest may be. In still other cases an equilibrium of decline may theoretically exist, but only at an interest rate far above the range of our practical experience. It is not very likely, therefore, that a real economy finds itself in an equilibrium of decline.

(2) The course of prices if the rate of interest is kept constant at various alternative rates is determined by again letting $\dot{r} / r=0$ and taking the derivative of (IV) with respect to $r$ :

$$
\frac{d}{d r}\left(\frac{\dot{p}}{p}\right)=\frac{\pi}{c r} \cdot \frac{\alpha}{r}\left[m-\frac{1}{1-\alpha}(1-c r)\left(\frac{\alpha}{r}\right)^{\frac{\alpha}{1-\alpha}}\right] .
$$

Lowering the rate of interest will be inflationary if, and only if, the expression in brackets is negative. At sufficiently low interest rates this condition is sure to be fulfilled since $\alpha / r$ can be made arbitrarily large by selecting ever lower rates of interest. It follows that there is indeed a certain "classical" range of interest rates within which the selection of a somewhat lower rate will be inflationary. In this range the classical doctrine is fully valid. Sufficiently high rates, on the other hand, are sure to make the bracketed expression positive. As a consequence, there must also be an "unclassical" range in which the selection of a lower rate would be deflationary. In this unclassical range cheaper money would once more result in cheaper bread. Between these two ranges there is a particular interest rate $\dot{r}$ at which the expression in brackets is exactly zero, making the pace of deflation a maximum. This is, figuratively speaking, the divide between the classical and the unclassical territories. The validity of the classical doctrine is thus seen to depend in a critical way on the range of interest rates we have in mind.

This argument is illustrated in fig. 3, which is simply the graph of (IV), with $\dot{r} / r=0$.

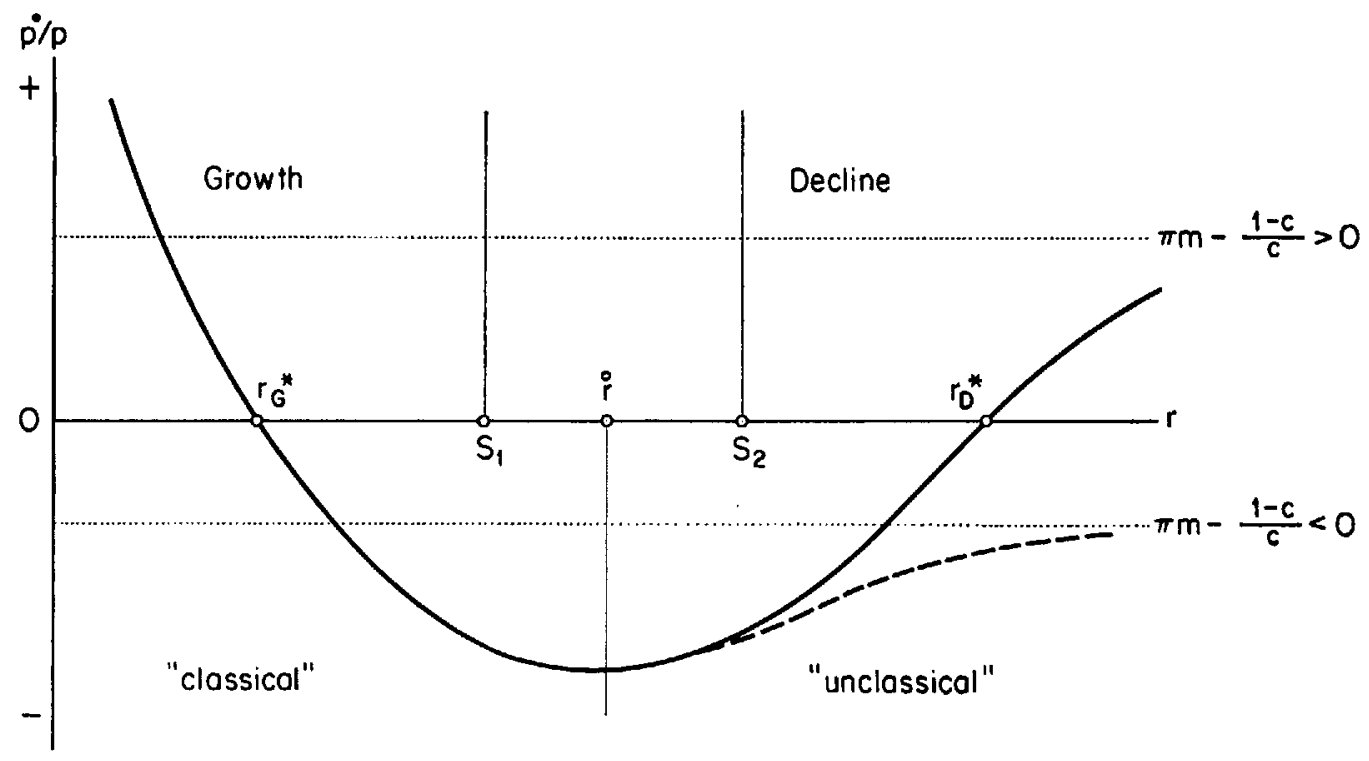

FIGURE 3

The broken line represents the (not unlikely) case where no equilibrium of decline exists. At the equilibrium rates $r^{*}{ }_{G}$ and $r^{*}{ }_{D}$ the price level is stable by definition. If rates are below the equilibrium of growth, we can be sure to have rising prices. The same is true above the equilibrium of decline, if there is one. To the right of the expansionary equilibrium, however, there is a range of price decline. To the left of the critical rate $\dot{r}$, any lowering of the rate of interest will be relatively inflationary by either accelerating inflation or slowing down deflation, while to the right of $\dot{r}$ a (small) reduction of interest will be 
relatively deflationary, slowing down inflation or, more probably, encouraging deflation. It is interesting to note that Wicksell, limiting his statements to deviations from the equilibrium rate, actually has a much better chance of being right than the classical doctrine in general, for the only point at which he could possibly be wrong is the rather unlikely one of an equilibrium of decline, while the general classical doctrine is wrong at any interest rate above $\stackrel{r}{r}$. There is also a "stagnation rate" $S$, defined by $X / L=m$, at which economic growth is zero, thus dividing the area of growth (to the left) from the area of decline (to the right). As far as our model is concerned, $S$ may be either on the left $\left(S_{j}\right)$ or on the right $\left(S_{2}\right)$ of $r$. Even growing economies thus cannot be certain that a lowering of interest rates would not have paradoxical effects on the course of prices.

If a vigorously growing economy is suffering from inflationary pressure, it can be sure to be on the left of $r^{*}{ }_{G}$. It may, therefore, safely rely on the classical doctrine. The same would often be true in deflationary situations with unsatisfactory growth (i.e. between $r^{*}{ }_{G}$ and $\stackrel{\circ}{r}$ ). Stimulating growth by lower interest rates would then arrest deflation or even change it into an inflationary pressure. It may happen, however, that in a situation of this kind a reduction of interest rates would on the contrary raise per capita income and accelerate growth without any sacrifice in the form of inflationary pressure and indeed an increase in the long-range fall of prices (i.e. between $\stackrel{\circ}{r}$ and $r^{*}{ }_{D}$ ). The classical doctrine would then be a bad guide for monetary policy. It is conceivable that an economy might even suffer from an economic decline accompanied by inflation (i.e. to the right of $r^{*}{ }_{D}$ ). In this case it could take consolation from the fact that there are sure to be some lower rates of interest which would not only allow for growth but also stop inflation. Since it is hard to find plausible values of the parameters producing this result, this extreme case may be of more interest to the theorist than to the policy-maker.

(3) So far the analysis was restricted to the consequences of keeping interest rates constant at various alternative levels. We now have to consider the effect of continuing changes in interest rates $(\dot{r} / r \neq 0)$. Taken in isolation, a fall in interest will be practically sure to push prices upward and vice versa. This is exactly as in the Solow-type model. If the lowering of rates is taking place in a " classical " situation, this dynamic component will simply add to the inflationary pressure arising from the progressively lower level of interest. If, on the other hand, interest is lowered in an " unclassical " environment, the deflationary effect of lower levels of interest will partially or totally offset the inflationary effect of their going down. As a consequence, a long-range deflationary effect can even be reconciled with a continuing reduction of interest rates. All we have to do is to let the rate fall asymptotically toward some level which is sure to produce deflation. In this way we can be certain that sooner or later the deflationary effect of the interest level will overbalance the inflationary effect of the lowering of rates. ${ }^{I}$ This is hardly a result of practical importance, to be sure, but it highlights the very unclassical conclusions which may be obtained from a seemingly quite classical model.

\section{Concluding Remarks}

This paper was not intended to present a complete theory of the effect of interest rates on prices in the course of economic growth. Many elements which might be of significance in such a theory such as the effects of interest rates on the propensity to save, the rôle of price expectations, price rigidities and underemployed factors, lags in the adjustment of different prices, and between the planning of investments and their completion were disregarded. The purpose of this paper was more limited. It was intended to examine to what extent, even in models constructed from the most classical buildingblocks the adoption of a long-run growth perspective might upset the classical proposition, usually derived in a short-term context, that cheap money makes dear bread. This purpose

\footnotetext{
${ }^{1}$ Dr. Dietman Onigkeit helped me with the mathematical proof of the statement in the text. This proof is not presented here.
} 
could, I think, best be reached by stripping the problem to its bare essentials. The main conclusions may be summarized as follows:

(1) The total effect of a reduction of interest on prices can be split up into two components, one of which arises from the fall in interest rates in the course of time whereas the other is related to the lower level of interest.

(2) The first component, connected with the name of Cassel, can practically be relied upon to work in the classical direction, but-except for possible lag phenomena-it is limited to the time when interest rates are actually going down. It is thus essentially of a short-term nature and gives no support to Wicksell's propositions.

(3) What Wicksell and other proponents of the classical doctrine seem to have had in mind is rather the effect of lower levels of interest. It is not certain, however, that this effect will work in the classical sense. As a consequence, it is quite conceivable that at lower levels of interest prices will finally be lower than if rates had been maintained at a higher level. This can be attributed to the fact that in the long run lower interest rates may stimulate the expansion of capacity more than they stimulate demand.

(4) While from a theoretical point of view, these unclassical possibilities may be somewhat disturbing and perhaps intriguing, their significance for monetary policy is limited in several ways. First, aside from quite unlikely cases, they only apply to situations where prices are falling to begin with; for situations of rising prices the rule of the classical doctrine is hardly weakened. Second, even if prices are falling, unclassical reactions only appear in the case of capital-poor economies with relatively high interest and low growth rates. Third, if interest rates are used as a short- or medium-term instrument, the direction of their change being reversed every few years, any unclassical reactions would tend to be washed out in the long run and the picture would be dominated by the Cassel-effects which are sure to work in the classical direction.

University of Zürich

JÜrg NIEHANS.

\section{BIBLIOGRAPHICAL REFERENCES}

[1] Beckmann, Martin. “Economic Growth and Wicksell's Cumulative Process", Cowles Commission Discussion Paper No. 120, 1961.

[2] Cassel, Gustav. Theoretische Sozialökonomie, 4th ed., Leipzig, 1927.

[3] Hahn, Frank H. "The Stability of Growth Equilibrium ", Quarterly Journal of Economics, vol. LXXIV, 1960.

[4] Hayek, Friedrich A. "A Note on the Development of the Doctrine of 'Forced Saving "," Quarterly Journal of Economics, vol. XLVII, 1932/33.

[5] Hayek, Friedrich A. Prices and Production, 2nd ed., London, 1935.

[6] Matthews, R. C. O. “ The Rate of Interest in Growth Models", Oxford Economic Papers, vol. 12, 1960.

[7] Niehans, Jürg. "Ueber die Wirkung der Zinspolitik auf die Güterpreise", Stabile Preise in wachsender Wirtschaft-Erich Schneider zum 60. Geburtstag, ed. Bombach, Tübingen, 1960.

[8] Niehans, Jürg. "Economic Growth with Two Endogenous Factors", Quarterly Journal of Economics, vol. LXXVII, 1963.

[9] Solow, Robert M. "A Note on the Price Level and Interest Rate in a Growth Model ", Review of Economic Studies, vol. XXI, 1953/54.

[10] Solow, Robert M. " A Contribution to the Theory of Economic Growth ", Quarterly Journal of Economics, vol. LXX, 1956.

[11] Tobin, J. "A Dynamic Aggregative Model", Journal of Political Economy, vol. LXIII, 1955.

[12] Wicksell, Knut. Interest and Prices, transl. by R. F. Kahn, London, 1936.

[13] Wicksell, Knut. Lectures on Political Economy, ed. Robbins, 2 vols., London, 1935. 